\title{
Cleodon Silva e a Casa dos Meninos: mecanologia, do reco-reco à internet
}

Guilherme Flynn Paciornik

Universidade Metodista de São Paulo

Pedro Peixoto Ferreira

Universidade Estadual de Campinas

\section{Resumo}

Este texto busca narrar o encontro feliz das trajetórias do ativista Cleodon Silva e da instituição Casa dos Meninos, e como esse encontro pode nos ajudar a repensar o papel daquilo que Gilbert Simondon chamou de "mecanólogo" ou "tecnólogo": aquele que estuda os indivíduos técnicos completos, que introduz na cultura "a consciência da natureza das máquinas, de suas relações mútuas e de suas relações com o homem, e dos valores implicados nestas relações".

Palavras-Chave: Gilbert Simondon; mecanologia; Casa dos Meninos

\begin{abstract}
This paper is about the happy encounter of the trajectories of activist Cleodon Silva and the institution Casa dos Meninos, and about how this encounter allows us to rethink the role of what Gilbert Simondon called the "mechanologist" or "technologist": one who studies complete technical individuals, who introduces in culture "the consciousness of the nature of machines, of their mutual relations and of their relations to man, and of the values implicated in these relations".
\end{abstract}

Keywords: Gilbert Simondon; mechanology; Casa dos Meninos.

Filosofia e Educação - ISSN 1984-9605

Volume 6, Número 3 - Outubro de 2014 
A Casa dos Meninos é um

laboratório de construção do novo.

Silva

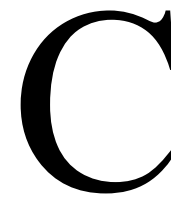

onsideramos que a história de Cleodon Silva e da Casa dos Meninos merece ser contada. ${ }^{1}$ Desde a década de 1980, Cleodon Silva (1949-2011; doravante Silva) usou, de forma ao mesmo tempo sistemática e inventiva, diversas tecnologias da informação e da comunicação (TICs; do reco-reco à internet) para, entre outras coisas: combater a ditadura; organizar a oposição sindical metalúrgica; organizar o sistema público de creches na gestão da prefeita Luiza Erundina em São Paulo; identificar individualmente empresas poluidoras da bacia do Rio Tietê; organizar espaços de lutas pelos direitos da criança e do adolescente; organizar a juventude em comunidades de periferia; e para a discussão de educação. Já os integrantes da Casa dos Meninos, entidade sediada no Jardim São Luis, na zona sul de São Paulo, compartilharam os últimos 12 anos de luta de Silva e continuam desenvolvendo suas próprias teorias e ferramentas tecnológicas de luta cotidiana. A partir do tripé juventude, tecnologia e território, organizam a população local em diversas lutas, e se apropriam de forma não proprietária da tecnologia, desenvolvendo, a partir das discussões na comunidade, sistemas de informação, mapas, sites, cruzamento de bancos de dados e ferramentas diversas. Criaram antenas wifi de latas e uma rede local não-proprietária de internet, e um projeto em andamento de criar uma intranet. Realizam atividades de formação com jovens da comunidade sobre software livre, georreferenciamento e tecnologias audiovisuais. Digitalizaram todo o acervo didático de uma escola da região e discutem uma proposta emancipadora de educação, que vise à autonomia intelectual e que compreenda o território e as tecnologias,

1 Este texto é uma versão alterada de passagens de Paciornik (2013).

Filosofia e Educação - ISSN 1984-9605

Volume 6, Número 3 - Outubro de 2014 
em oposição a um tipo de educação voltada à formação de mão-de-obra. Foram capazes, por exemplo, de criar movimentos sociais em prol de creches a partir de georreferenciamento e visualização, por parte da população, das desigualdades vivenciadas, feito alcançado em 2008. Ambos, Silva e a Casa dos Meninos, querem resgatar a tecnologia do capital e devolvê-la de forma não alienada para a população.

Este texto buscará narrar o encontro feliz dessas duas trajetórias, de Silva e da Casa, e como esse encontro pode nos ajudar a repensar o papel daquilo que Gilbert Simondon chamou de "mecanólogo" ou "tecnólogo": aquele que estuda os indivíduos técnicos completos, que introduz na cultura "a consciência da natureza das máquinas, de suas relações mútuas e de suas relações com o homem, e dos valores implicados nestas relações"; "um psicólogo [...], ou um sociólogo das máquinas" (Simondon 1969, p. 13; p. 149).

[O] estudo dos esquemas de funcionamento dos objetos técnicos concretos apresenta valor científico porque esses objetos não são deduzidos de um único princípio; são o testemunho de um certo modo de funcionamento e de compatibilidade que existe de fato, e que foi construído antes de haver sido previsto: esta compatibilidade não estava contida em cada um dos princípios científicos separados que serviram para construir o objeto; foi descoberta empiricamente; da constatação desta compatibilidade se pode remontar às ciências separadas para colocar o problema da correlação de seus princípios e fundar uma ciência das correlações e das transformações, que seria uma tecnologia geral ou mecanologia" (Simondon, 1969, p. 48) 
A ciência da mecanologia e a profissão do mecanólogo teriam impactos, assim, para a própria comparabilidade entre as ciências, e por essência ajudariam na superação do hiato entre as chamadas ciências exatas e as chamadas ciências sociais, sendo fundamentais na construção de uma sociologia "transindividual".

O mecanólogo, para Simondon (1969, p. 151), teria como tarefa "ser o representante dos seres técnicos frente àqueles através dos quais se elabora a cultura; escritores, artistas". Poderíamos certamente perguntar o que acontece se pluralizarmos esta "cultura" (em, por exemplo: cultura acadêmica, cultura digital, culturas indígenas etc.). Neste caso, quais atores cumpririam a tarefa de representar os seres técnicos frente àqueles que participam da elaboração das "culturas políticas de esquerda"? Consideramos que a história de Silva e da Casa dos Meninos merece ser contada, entre outras coisas, pois ela oferece respostas possíveis para esta pergunta.

\section{Cleodon Silva, militante histórico e mecanólogo²}

Silva nasceu em 1949, na cidade de Garanhuns, Estado de Pernambuco, filho de um enfermeiro e uma servente do hospital local. Aspectos de sua infância e de sua vida familiar, como o impacto que teve nele a relação de

2 Considerável parte do histórico a seguir, bem como todos os trechos que figuram como citações, foram extraídos da entrevista com Silva realizada pela pesquisadora Agnes Mariano, em 2009, e publicada na íntegra em Paciornik (2013, p. 179-213). Complementam o texto documentos do Instituto Lidas, material presente no site do Intercâmbio, Informações, Estudos e Pesquisas (IIEP) e anotações a partir de conversas com Silva.

Filosofia e Educação - ISSN 1984-9605

Volume 6, Número 3 - Outubro de 2014 
seu pai com o lixo, ${ }^{3}$ com a natureza, ${ }^{4}$ e com a sabedoria popular, ${ }^{5}$ chamam a atenção pelo que já anunciam de uma prática política e social atenta aos imperativos sociotécnicos e ambientais. No mesmo sentido, chama a atenção um episódio ocorrido aos seus 12 anos, quando colocou sua motivação e engenhosidade tecnopolítica a serviço de uma vingança arquitetada contra um professor autoritário de latim que o havia expulsado da sala de aula.

Isso me causou uma revolta tremenda. Aí, a minha cabeça se voltou só para pegar esse professor. A vontade que eu tinha era dar um cacete, dar umas pancadas nele, mas, como não podia... [...] Mas aí, eu disse: "Vou pensar". Foi a primeira vez que eu pensei em atacar uma pessoa. [...] Comecei a estudar as possibilidades de prejudicar aquele professor. [...] Fiz três tentativas de acabar com o carro dele. Primeiro, tentei furar o pneu com bica de garrafa quebrada. Coloquei lá, mas não deu certo. Também cheguei a amarrar um monte de latas de óleo vazias no arame e amarrei embaixo do carro, no eixo. Quando ele saiu: "Pá, pá, pá". A turma: "Ehhhh". [...] Depois comprei um prego [...] que era maior que o meu dedo. Coloquei numa madeira, deixei ele ultrapassando a madeira, pulei o muro da

3 Silva considerava "impressionante [...] o tratamento que meu pai dava ao lixo. [...] O lixo orgânico não sai de casa, sempre fica. Ele tem vários buracos. Vai cavando buraco, vai enterrando. Quando enche, abre outro, depois volta para aquele primeiro, mas o lixo orgânico não sai de casa. Até hoje. Ele está com 94, 95 anos.” (Silva, in: Paciornik, 2013, p. 180).

4 Quando criança, Silva "tinha contato com a natureza, todos os animais, sempre foi um contato muito forte. Tratei de animal, andei de cavalo, jumento, carregava água com jumento, carregava capim. Tive um contato forte com o campo. [...] Plantava macaxeira, mandioca, feijão, milho.” (Silva, in: Paciornik, 2013, p. 180).

5 Silva conta que o pai "[d]izia que, quando você está falando com um matuto, se você fala ou pergunta alguma coisa, ele fala: 'Sinhô?' -, dando espaço pra você repetir a pergunta. Mas ele já não estava mais ouvindo, estava pensando na resposta. Ele ganha um tempo. Não tem nada de burro, pelo contrário. Ele [o pai de Silva] sempre destacou algumas atitudes de sabedoria do homem do campo." (Silva, in: Paciornik, 2013, p. 180).

Filosofia e Educação - ISSN 1984-9605

Volume 6, Número 3 - Outubro de 2014 
escola e fui lá. Ele colocava o carro encostado na parede, tinha que sair de ré. [...] Passei o prego de ponta a ponta na lateral [do carro] e deixei o prego lá. E quando ele foi sair, furou o pneu do carro. [...] Aí eu fiquei tranquilo. (Silva, in: Paciornik, 2013, p.181)

Como muitas vezes faria ainda em sua vida, diante de um problema, Silva voltou sua atenção para o sistema de causalidades recíprocas envolvido, buscando nas agências imanentes ao próprio campo problemático o motor de sua reconfiguração. Como também outras vezes ocorreria, a maquinação desejante de Silva não o livrou de algum constrangimento, mas mais importante do que isso parece ser esse singular encontro de intuição e inteligência, que desde a infância contribuiu para formar esse mecanólogoativista tão singular.

Já adolescente, um ano antes do golpe militar de 1964, começou a se envolver com representação política estudantil secundarista. Nos dias do golpe, 31 de março para $1^{\circ}$ de abril de 1964, o jovem ajudou a interromper as atividades na escola e a espalhar cartazes de greve pela cidade. Foi então que viu pela primeira vez, no sindicato dos bancários locais, um mimeógrafo, objeto técnico marcante para suas futuras atividades. ${ }^{6}$ Nesse mesmo dia, viu também a violência política pela primeira vez: os militares encheram a rua de metralhadoras, invadiram o sindicato dos bancários e fizeram uma fogueira na rua com todos os livros ali encontrados. Até então, Silva se destacava na disciplina de Física - "dava aula para a minha classe" -, depois deu uma "virada total": "abandonei as chamadas ciências exatas e comecei a estudar e a procurar filosofia, política, sociologia. Mudei

6 O mimeógrafo (na verdade um "reco-reco") seria uma máquina reprodutora chave para ele, a partir de meados dos anos 1970, "articular o pensamento coletivo sobre as questões de interesse dos trabalhadores" (Silva, in: Paciornik, 2013, p. 196), principalmente na forma de jornais, informes de fábrica e cordéis.

Filosofia e Educação - ISSN 1984-9605

Volume 6, Número 3 - Outubro de 2014 
totalmente o rumo." (Silva, in: Paciornik, 2013, p. 181)

Silva passou os dois anos seguintes praticamente internado na biblioteca local, estudando política, filosofia, sociologia, entre outros temas. Em 1967, Nilmário Miranda (que posteriormente foi Secretário de Direitos Humanos do Governo Lula) chegou a Garanhuns com material de propaganda marxista, que foi devorado pelos jovens locais alinhados mais à esquerda, incluindo Silva. Ainda em 1967, Silva participou da organização do congresso da União Brasileira dos Estudantes Secundaristas (Ubes) no Estado de Pernambuco. Nesse encontro, duas particularidades o marcaram. A primeira foi o uso do rádio: em dado momento do congresso, um estudante conseguiu sintonizar a Rádio Havana e todos ouviram um discurso de Fidel Castro. A segunda particularidade foi a premência do que Silva entendia como "situação concreta". Durante o congresso, as discussões orbitavam na aliança operário-estudantil-camponesa e em oposição ao acordo MEC-USAID, que se lia como uma infiltração imperialista no ensino brasileiro. Silva então pediu a palavra e levantou o problema da situação concreta do aluno na sala de aula e das dificuldades encontradas nos locais de ensino, pois avaliava que, embora os pontos até então discutidos fossem importantes, eles ficariam no abstrato, não desceriam aos problemas da forma como eram percebidos pelos alunos no dia a dia:

O congresso não estava dando resposta nenhuma à situação concreta do aluno na sala de aula e às dificuldades encontradas pelo local de ensino, local de estudo. Eu intervi e me surpreendi também com um monte de gente que, quando eu levantei a questão, veio imediatamente em meu apoio. A questão das lutas específicas começou a ter lugar dentro do congresso. Mas foi

Filosofia e Educação - ISSN 1984-9605

Volume 6, Número 3 - Outubro de 2014 
aos empurrões que isso aconteceu, porque, se deixasse no ritmo lá, ia ficar só nas questões gerais e não ia descer. Essa foi também uma coisa: eu verifiquei que o pensamento na situação concreta é importante. Se tirar isso, vai ficar etéreo. Vai ficar sem lugar. (Silva, in: Paciornik, 2013, p.185).

A importância de pensar na situação concreta num congresso da Ubes não parecia ser diferente, em Silva, do que a mesma preocupação no ensino de ciências na escola. Em ambos os casos, se trata de: "desocultar a realidade e intervir o mais próximo possível da situação concreta. Aquela famosa questão do Marx da análise [...] da situação concreta" (Silva, in: Paciornik, 2013, p. 209). Retomando o momento em que deixou a Física de lado para se dedicar a "filosofia, política, sociologia", Silva afirma que "toda ciência tem que ser verificada", e lamenta não ter tido mais acesso à dimensão experimental da ciência em sua formação escolar:

Em todo o meu processo, entrei no laboratório uma vez para ver algumas cobras lá no fenol, em conserva. Mas, fora disso, todo aquele monte de equipamentos, tubos de ensaio, tudo parado, cheio de poeira. Nunca vi um exercício, nunca passei por um exercício de química no laboratório, nem de física. Tudo que a gente aprendia teoricamente não tinha como verificar, não tinha como exercer e me dava aquela sensação horrorosa de que eu sempre iria ficar sabendo que alguém fez em algum lugar do mundo. Que iam me ensinar, de uma forma teórica, mas eu não tinha condição nenhuma de seguir uma experiência, de desenvolver outra. Isso era frustrante. Perdi o tesão totalmente. (Silva, in: Paciornik, 2013, p. 209). 
Naquele mesmo congresso da Ubes, em 1967, Silva recebeu de outro militante dois livros que o marcam: A concepção materialista de História, de Plekhanov, e $A B C$ do Comunismo, de Bukharin. Devorou ambos e passou a se afirmar, já sem dúvida alguma, como comunista.

Em 1969, ingressou no Grupo Armado de Propaganda (GAP), sua primeira agremiação de esquerda. Em uma ação no Recife, participou de um tiroteio contra as forças do regime. Nesse momento, Silva também se aproximou politicamente da Política Operária (Polop), a qual passou a integrar. Ainda em 1969, criticando a falta de ação e o excesso de estudo que via na Polop, passou para o Partido Comunista Brasileiro Revolucionário (PCBR), onde foi designado para compor a Comissão de Campo. Isso porque, naquele ano Silva havia começado a trabalhar em uma entidade dirigida pelas mulheres dos usineiros pernambucanos, a Cooperar na Arte (Cooperarte). A vivência o fez tomar contato com as condições dos trabalhadores do plantio de cana-de-açúcar no Estado. Realizou então, pela primeira vez, um feito que, muitos anos depois, repetiria: transformou um trabalho de caráter assistencialista, para o qual havia sido convidado, em um trabalho de formação política. Não durou muito no emprego: logo numa das primeiras reuniões de discussão política que promoveu no horário de trabalho, foi interrompido por um capataz com uma espingarda calibre $44 \mathrm{e}$ um revólver .38 e, após ser "gentilmente" carregado de jipe para Recife, foi demitido.

Em 1970, Silva começou seu primeiro trabalho com dados públicos, por meio de um concurso da Fundação Instituto de Administração Municipal (Fiam), onde atuou no plano plurianual da cidade de Caruaru para os anos de 1971 e 1972. Ainda em 1970, saiu da Comissão de Campo e decidiu ir para a Comissão de Fábrica do PCBR. Ninguém de sua célula política concordava com o deslocamento, mas isso não impediu que o 
militante o realizasse mesmo assim. Por meio de um contato, Zé de Brito, junto à Aliança Libertadora Nacional (ALN), do militante Carlos Marighella, conseguiu um emprego numa fábrica de fertilizantes. Quando Zé de Brito e os demais militantes da ALN naquela fábrica foram presos, Silva descobriu que a ALN estava fabricando, em turno extra e com as mesmas máquinas que lá havia, espingardas (das diversas peças até a munição), graças à inventividade de um ferreiro militante que lá trabalhava e ao qual Silva inclusive ensinou a escrever o próprio nome. Depois dessa experiência, Silva ainda trabalhou em diversas fábricas, por quase vinte anos.

Como o clima no Recife estava crescentemente tenso - e Silva já aparecia em sete processos com seu nome de guerra -, por sugestão e com ajuda de um padre da Ação Católica Operária, Silva veio para São Paulo. Antes de partir, foi praticamente expulso do PCBR por se recusar a revelar o paradeiro de um militante que estava com a morte decretada pela própria organização. Chegou a São Paulo em 1971, com contatos junto à Polop e à Pastoral Operária, destacadamente Waldemar Rossi, militante renomado. Numa solução engenhosa, passou a adotar o próprio sobrenome como nome de guerra: "Comecei a usar o sobrenome: Silva. E Silva é o anonimato assinado. Isso me ajudou bastante" (Silva, in: Paciornik, 2013, p. 190).

Silva seguiu o trabalho nas fábricas, e paulatinamente foi se aproximando da gestão de processos, do controle de qualidade, ${ }^{7}$ mais uma

7 Tal aproximação teve um desdobramento interessante na ocasião de sua demissão de seu último emprego fabril, em 1993. Apesar de ter demitido Silva pelo seu envolvimento e papel de liderança no movimento grevista da fábrica, a direção da fábrica justificava a demissão pelo não cumprimento do período de experiência. O problema é que todos sabiam que Silva tinha plenas condições de passar pelo período, principalmente depois que ele resolveu, com sua engenhosidade e controle estatístico, um antigo problema da fábrica: "[E]les disseram que eu não passei na experiência. Uma mentira a toda prova, porque toda a fábrica ficou sabendo que eu resolvi uma questão de quase 10 anos na fábrica, um erro que estava dando e por controle estatístico eu localizei onde era o problema e evitei que um monte de prejuízo fosse dado para a fábrica. Inclusive eles se assustaram. Muita gente lá

Filosofia e Educação - ISSN 1984-9605

Volume 6, Número 3-Outubro de 2014 
manifestação do interesse perene de Silva no sistema de causalidades recíprocas imanentes aos processos com os quais estava lidando:

Depois que eu saí da fábrica de móveis de aço, fui para uma fábrica de produção de embalagens de cosméticos: aerosol. [...] Ali eu estava no controle de qualidade e me interessei muito [...], principalmente na parte estatística, no controle estatístico de qualidade. Pelas manifestações dos fenômenos, das falhas que se davam durante a operação e como se davam, onde se davam, o tempo em que se davam. O registro dessas falhas dava uma orientação de como você abordar o problema e onde é que estava sendo provocado mais falhas. Se era o ferramental, se era a forma de fazer, enfim, várias pistas para melhorar a qualidade, evitar estragos e refugo na produção. (Silva, in: Paciornik, 2013, p. 190)

Sempre trabalhando clandestino na organização de trabalhadores, começou a compreender e a se interessar mais e mais pelos processos produtivos. Conta que, certa vez, um sócio da Ardea, a empresa onde então trabalhava, lhe mostrou um máquina gigantesca que tinham acabado de perder, pois um processo novo, um simples conta-gotas de plástico, a tinha tornado completamente desnecessária. "Para mim, foi uma aula de produção, do sucateamento das coisas. Uma inovação, a invenção do contagotas, sucateou uma máquina que tinha o tamanho de um quarteirão", recorda o militante, e complementa:

ficou também numa situação difícil, porque já vinha esse problema lá há 10 anos e ninguém tinha conseguido resolver. Localizavam, identificavam a falha como sendo de um local, quando não era desse local, era de um local anterior. Mas como eu fiz um controle estatístico desde o começo, fui pesando e vendo as coisas, eu localizei exatamente onde estava, onde se dava a falha. E eles ficavam o tempo todo investindo, achando que era uma máquina, quando não era. E isso foi uma coisa assim que eles se assustaram. E eu que tinha resolvido, com menos de um mês de fábrica." (Silva, in: Paciornik, 2013, p. 200).

Filosofia e Educação - ISSN 1984-9605

Volume 6, Número 3 - Outubro de 2014 
Quando vi aquela coisa toda, a dinâmica da produção, eu ficava me perguntando quais as informações necessárias e como os trabalhadores iriam dar conta de assumir. Não só a questão do domínio da técnica, mas saber a hora que interessa a substituição de uma tecnologia por outra. Como operar tudo isso e tomar decisões políticas que iriam implicar em uma economia, ou impacto no meio ambiente, ou, enfim, todas essas questões que são colocadas. Tinha gente que trabalhava lá há 10 anos e nunca conheceu o outro lado da fábrica. Nem sabe, nem consegue ter na cabeça o fluxo da produção da fábrica em que trabalha. (Silva, in: Paciornik, 2013, p. 192).

Silva se preocupava com a compreensão limitada que os trabalhadores tinham do processo produtivo no qual estavam envolvidos, e acreditava que a luta dos trabalhadores não deveria se limitar à busca de melhores salários, mas deveria envolver também a busca de melhores condições de trabalho e de vida, dentro e fora da fábrica, no seu bairro, no seu ambiente. Por esse tempo, Silva começou a refletir também sobre o impacto que a adoção de novas tecnologias causava na saúde do trabalhador, observando que, "no Brasil, a violência da produção capitalista tem números de uma guerra civil". Outro exemplo que utilizava, mais recentemente, era o das nanotecnologias, alertando para seu difundido uso em contraste com o fato de não haver "nenhum estudo do que é que essas nano-partículas vão provocar no organismo" (Silva, in: Paciornik 2013:192).

Em fins de 1972 e início de 1973, o militante integrou a primeira turma do curso de metalurgia do Senai e passou a trabalhar na Vidraria Santa Marina, onde participou de mais uma série de cursos. 
Então, aprendi. Eu [...] entrava dentro de uma fábrica, batia o olho e já fazia, já identificava na hora todos os circuitos: elétrico, hidráulico, pneumático. Enfim, todos os fluxos da fábrica eu imediatamente levantava. (Silva, in: Paciornik, 2013, p. 192).

Sua curiosidade se desenvolveu cada vez mais, e Silva terminou por aprofundar-se no tema da automação pneumática e, a partir daí, no processo de retroalimentação:

Isso me chamou muito a atenção. A questão de um sinal que se emite, chega em determinado local, produz algo que, por sua vez, manda o sinal que devolve o sinal. A questão da retroalimentação foi uma coisa que me marcou muito e eu fiquei com aquilo na cabeça. No sentido de utilização dessa questão em outras áreas. (Silva, in: Paciornik, 2013, p. 193).

Apesar de ter efetivamente usado esse conhecimento sobre automação pneumática aparentemente apenas uma vez em toda a sua trajetória fabril, ${ }^{8}$ parece inegável que o envolvimento de Silva com a automação e ao mesmo tempo com o movimento sindicalista o colocava em sintonia com o estado da arte na indústria nacional e em plenas condições de representar os seres técnicos frente àqueles que participam da elaboração

8 Vale citar o relato de Silva sobre essa ocasião, vivida numa fábrica de máquinas impressoras de sacos plásticos: "Eu lembro que eles estavam atrasados para fazer a entrega para o Canadá de uma máquina dessas e não tinha ninguém para fazer o circuito pneumático. Aí eu assumi o desafio. Eu trabalhava para outra função, eles não sabiam disso. Eu digo: 'Eu consigo montar o circuito se vocês me derem o desenho'. Passei uma noite aprontando, montando o circuito pneumático dessa máquina, que foi para o Canadá. É um conhecimento que eu tinha que estava morto. Eu carregava ele, mas sem aplicação. Aí eu tive a oportunidade. Para mim foi uma satisfação individual. Quando é que eu ia ter a oportunidade de montar o circuito de uma máquina? Nunca isso ia acontecer. E eu consegui realizar." (Silva, in: Paciornik, 2013, p. 198).

Filosofia e Educação - ISSN 1984-9605

Volume 6, Número 3 - Outubro de 2014 
das "culturas políticas de esquerda".

Silva também atuou na direção do movimento de Oposição Sindical Metalúrgica de São Paulo (OSM), grupo de oposição ao chamado "sindicalismo pelego", entre 1971 e 1972, afastando-se e retornando em 1975. A OSM tinha uma visão particular e crítica ao modo tradicional de se fazer sindicalismo, mesmo quando comparada a grupos de esquerda. À proposta do grupo de metalúrgicos do $\mathrm{ABC}$ e de seu presidente Lula da necessidade de um "representante sindical", contrapunham a proposta de "comissão de fábrica". As referências políticas para as formulações da OSM e de Silva eram, entre outras, a Comuna de Paris, os sovietes, os Comitês de Turim, experiências nas quais a construção pela base surgia como um dos elementos centrais. Novamente a dimensão local, de ligação com a base, aparece na biografia de Silva.

Em 1975, começou a desenvolver formas de comunicação operária:

Chegava em casa, tinha uma máquina de escrever, estêncil, fazia tudo no estêncil ainda. Eu escrevia o boletim, datilografava no estêncil, rodava e ainda conseguia colocar alguma figura. Desenhava uma figura no estêncil. Tem uma técnica especial para isso. Rodava no reco-reco, não era nem mimeógrafo. Eu tirava 100 cópias em 20 minutos, saía como se tivesse sido feito numa gráfica. A qualidade do boletim [era tal, que] você olhava e pensava que saía de um offset ou de um mimeógrafo elétrico. (Silva, in: Paciornik, 2013, p. 195).

Silva buscou, nos turnos, o melhor momento para distribuir os boletins sem ser visto, e escolheu o horário do almoço, quando a chefia não poderia saber, ao certo, se alguém da turma da manhã tinha deixado o material, ou se tinha sido trazido por alguém da turma da tarde. Trabalhando 
na Arno, Silva fazia os boletins sozinho, articulando uma série de conhecimentos e experiências em um conjunto coerente que ele sabia operar com a precisão e a consistência de um mecanólogo.

É a questão da criatividade e da análise [...] das possibilidades do momento. Quer dizer, eu aprendi a tecnologia de imprimir, os macetes da relação dentro da fábrica, os fluxos. Não existia um método para se chegar a isso, não existia nenhuma metodologia para isso, mas eu estava desenvolvendo, desenvolvi todo um conjunto. Aliás, articulei todo um conjunto de conhecimentos que me permitia fazer esse tipo de coisa. (Silva, in: Paciornik, 2013, p. 195).

Entre 1978 e 1989-90, Silva produziu e distribuiu cordéis militantes pelos espaços operários e políticos da cidade, sempre com uma imagem na capa e com uma poesia sobre a luta, a situação de classe e a situação política - situação que poderia advir de uma fábrica ou do Brasil como um todo. Os cordéis eram assinados por um nome desconhecido, Pedro Macambira, ${ }^{9}$ e tinham títulos sugestivos, como: $O$ candidato honesto que engana todo mundo (1978), Conversa de três pelegos com satanás (1978), Nós e os patrões, um desafio de morte (1979), A aparição de Paraíba e os abusos da Jurubatuba (1980), A greve da Barbará e o carrasco Diamantino (1983) e Reco-reco: máquina de bater em patrão (1985), ${ }^{10}$ este último um cordel no qual ensina os operários a construir sua própria imprensa, inclusive com plantas técnicas da construção de reco-recos. ${ }^{11}$

9 Apenas em 1985, Silva admitiu ser Pedro Macambira seu pseudônimo.

10 Anos depois, esse material foi coletado e impresso, com prefácio do sociólogo Florestan Fernandes. Os cordéis e o prefácio estão disponíveis no site: $<$ http://www.iiep.org.br/index1.html>. Acessado em: 13 de setembro de 2014.

11 Vale citar aqui uma passagem desse cordel em que Pedro Macambira aborda aquilo que Laymert Garcia dos Santos (2003) chamou de "virada cibernética", da perspectiva do

Filosofia e Educação - ISSN 1984-9605

Volume 6, Número 3 - Outubro de 2014 
Em 1978, Silva vivenciou ativamente sua primeira greve. Trabalhava, então, na metalúrgica Barbará, na zona sul de São Paulo. Nesse período, desenvolveu outros mecanismos de comunicação operária interna à fábrica: comprava os jornais, tirava fotocópias e montava uma publicação alternativa. Silva orquestrou todo um conjunto técnico para promover a reflexão de seus companheiros, uma "técnica para o enfrentamento" ao lado de tantas outras mobilizadas por ele em favor da luta dos trabalhadores (cf. Paciornik, 2013, p. 199).

[C]hegava cedo, comprava o jornal e, nas minhas idas ao banheiro, eu recortava os artigos e, com um bastão de cola, montava os artigos do jornal de interesse ali. Inclusive, quando estava anunciando as primeiras greves, eu montava um jornalzinho dentro do banheiro da fábrica, cortando, e colocava em um plástico. [...] Aí colocava dentro de uma pasta de desenho e, na hora do almoço, ia numa ótica que tinha perto, tirava 10, 15 cópias. No almoço já começava a circulação das notícias dos jornais que interessavam à luta dos trabalhadores. [...] Colocava as coisas e escrevia uma pergunta, alguma coisa entre uma matéria e outra. Com lápis, com caneta mesmo fazia, em letra de forma, algumas perguntas para orientar a discussão. E isso era de uma eficácia enorme. A gente colocava dentro de um plástico, porque o pessoal trabalhava muito com óleo [...]. De um lado estava o desenho [técnico da peça que estava sendo produzida], do outro lado, o boletim. O pessoal lia, inclusive, na hora do trabalho [...], mas se chegasse um chefe, um

"peão": "É lei do capital / A tudo controlar / Não deixar brexa nenhuma / Pro peão se levantar / Inventaram ferramenta e computador / Fizeram até robot / Para o peão não pensar". E outra, em que ele aponta para as relações entre a invenção e os conhecimentos envolvidos no processo de fabricação da "máquina de bater em patrão": "Siga as instruções / Que você vai acertar / Tela de nylon ou organdi / Tanto faz, pode pregar / Trabalhe com paciência / Usando sua ciência / Você vai até inventar".

Filosofia e Educação - ISSN 1984-9605

Volume 6, Número 3 - Outubro de 2014 
encarregado, qualquer coisa, era só virar a página com o desenho da peça que você estava produzindo. Então tinha esquemas de burlar a vigilância e o controle patronal. (Silva, in: Paciornik, 2013, p. 195).

Ainda em 1978, a OSM ganhou as eleições sindicais, mas não tomou posse. A ditadura interveio, através do Ministério do Trabalho, e empossou novamente Joaquim Santos Andrade, o "pelego" Joaquinzão, como presidente do sindicato. O documentário Braços cruzados, máquinas paradas, de 1979, dirigido por Roberto Gervitz e Sérgio Toledo, registra esse momento histórico, contando, inclusive, com uma fala de Silva no episódio dessa eleição sindical. Com a fama de ser da direção da OSM, somada ainda com a assunção da identidade de Pedro Macambira, começou a ficar cada vez mais difícil para Silva conseguir emprego em fábricas. Passou a ter de se transformar para cada entrevista: "Tive que aprender e desenvolver toda a técnica de falsificação de carteira profissional. A minha questão era falsificar para trabalhar”. (Silva, in: Paciornik, 2013, p. 199).

Em 1987, em mais uma disputa do sindicato dos Metalúrgicos, a OSM conseguiu a lista de filiados do Sindicato, e coube a Silva a "saga" de passar os dados daquela fita magnética para disquetes - na época $3: 4$, os "bolachões". Silva viajou até Belo Horizonte para transferir os dados na sede do sindicato dos bancários, tendo sucesso na operação e voltando a São Paulo com caixas e caixas de disquetes com a informação dos filiados. $\mathrm{Na}$ capital paulista, encontrou um programador que trabalhava com banco de dados, e acompanhou os passos desse profissional enquanto ele fazia a transferência e lia os disquetes. "Fiquei ouvindo o programador discutir com o computador como se este fosse uma pessoa, e [fiquei] pensando naquilo", relata. Foi a primeira vez que ouviu falar em banco de dados e em como 
organizar a informação.

Pouco depois, duas preocupações o levaram a procurar um programador. A primeira era a realização do mapeamento das empresas metalúrgicas na cidade, criando microrregiões, para que os militantes pudessem ter maior conhecimento das fábricas nesses espaços delimitados. A segunda, no campo da saúde, se tratava de referenciar os trabalhadores das fábricas ao sistema público de saúde. Isso era importante pois os médicos das fábricas, em lugar de assessorar os trabalhadores, frequentemente se limitavam a informar os patrões sobre as doenças, permitindo que estes demitissem funcionários antes que os sintomas se agravarem, o que criava obstáculos para demonstrar que um eventual problema de saúde fora causado pelo processo produtivo de uma fábrica específica, e responsabilizá-la por isso. O programador procurado então the explicou que, se a informação estivesse disponível no formato adequado, seria possível fazer uma programação que contemplasse as demandas de Silva.

Pronto, isso mudou minha vida. [...] Foi quando eu vi pela primeira vez a lógica da programação, a articulação dos códigos de programação. [...] Mudou tudo na minha vida. Tudo que eu estava fazendo, todos os limites que eu estava encontrando foram sendo quebrados (Silva, in: Paciornik, 2013, p. 203).

Silva foi aos poucos migrando para a discussão de sistemas de informação. É a partir daí que começa seu trabalho de localização da informação no espaço urbano, programando ainda em DOS e relacionando o dado que estava no computador com o mapa em papel que estava ao lado. Em 1988, fundou o Instituto Lidas - Ligas em Defesa do Ambiente e da 
Saúde, originariamente voltado para a questão do ambiente e saúde do trabalhador, mas que, a partir de 1990, começou a se dedicar também à questão de políticas urbanas com ênfase nos filhos de trabalhadores. O Lidas existe até hoje e sempre serviu como um ambiente de trabalho para Silva, auxiliando tanto em suas necessidades materiais como no financiamento das lutas nas quais se envolvia. ${ }^{12}$

Em 1992, pelo Instituto, Silva apresentou um projeto junto à ECO 92 que partia de uma ideia interessante e nunca antes realizada: fazer o cruzamento da malha urbana de ruas com o mapa de bacias e sub-bacias hidrográficas e com o cadastro industrial do Senai de empresas com mais de cinco trabalhadores. Na época, a representação na tela do computador ainda não era em mapas (não se visualizava com imagens gráficas), mas Silva fazia a transposição gráfica dos dados para mapas de papel.

\begin{abstract}
Numa sub-bacia, se eu encontrasse no córrego mercúrio ou chumbo, metais pesados, pelo código de atividade econômica das empresas daquela sub-bacia, eu inferia quem trabalhava com chumbo. Porque o código da atividade econômica diz o que produz. E pelo que produz você sabe se contém chumbo ou não. Com rápidas aproximações [...] eu estava com todas as empresas que destinavam os efluentes para o córrego sem tratamento. (Silva, in: Paciornik, 2013, p. 204).
\end{abstract}

Infelizmente, o projeto foi muito mal aceito pelos empresários e pela área do governo responsável pelo Programa de Despoluição do Tietê à época, pois a ideia central do programa não era, segundo Silva, a efetiva despoluição do Tietê:

12 Mais informações sobre histórico, funcionamento e outros dados do Lidas podem ser encontrados em: <http://www.lidas.org.br>. Acessado em: 13 de setembro de 2014.

Filosofia e Educação - ISSN 1984-9605

Volume 6, Número 3 - Outubro de 2014 
[O] programa de despoluição foi usado por uma determinada faixa de empresários, que tinha alguma influência, que pegava o dinheiro da despoluição do Tietê pra reequipar, fazer inovação tecnológica na maquinaria. Na verdade não foi para despoluir, foi utilizada essa grande massa de dinheiro por interesses particulares. (Silva, in: Paciornik, 2013, p. 204)

Em moldes semelhantes, durante o governo de Luiza Erundina na cidade de São Paulo, entre 1989 e 1993, Silva fez o georreferenciamento de crianças nas creches, cruzando os dados de localização de creches e de moradia e trabalho dos pais, de forma que as crianças pudessem ir de fato para a creche mais conveniente e com o menor deslocamento possível. ${ }^{13}$

Nós cadastramos todas as crianças que estavam em creches. Relacionei a moradia da criança com o trabalho do responsável dela: moradia e trabalho, do pai e da mãe. Então a gente sabia exatamente qual era a situação para racionalizar a utilização do sistema. Ou não se deslocar muito tempo com a criança nesses ônibus lotados. Tem muitos e muitos casos em que a mãe sai $5 \mathrm{~h}$ da manhã com a criança no colo. Poderia deixar a criança numa creche próxima da casa, evitaria o deslocamento da criança. (Silva, in: Paciornik, 2013, p. 204)

Outra experiência que o marcou foi georreferenciar, para o Sindicato dos Motoristas de São Paulo, todos os dados profissionais e de moradia dos filiados - quem era da comissão de garagem, quem era da Comissão Interna

13 Note-se que esse cruzamento de dados sobre moradia e local de trabalho para determinar escolas mais convenientes é algo que o sistema informatizado escolar público da cidade de São Paulo, o Educação OnLine, ainda não fazia até o ano de 2012.

Filosofia e Educação - ISSN 1984-9605

Volume 6, Número 3 - Outubro de 2014 
de Prevenção de Acidentes (Cipa) etc. "Foi um fiasco", conta Silva. Em um primeiro momento, os representantes do Sindicato ficaram maravilhados, mas, pouco depois, admitiram que fizeram um pacto para recusar o sistema. A justificativa era simples, conta Silva: "Porque se uma tendência (interna do sindicato) pegasse aquilo ia acabar com as outras. A questão da transparência, um monte de coisas ficava muito visível." (Silva, in: Paciornik, 2013, p. 205).

Foi uma grande decepção da minha vida. Quando eu descobri uma coisa que ia ajudar o enfrentamento e a luta dos trabalhadores, verifiquei que isso daí, dentro do movimento sindical, não tem vez. [...] Pode entrar qualquer coisa, mas [...] transparência, não [...] entra nesse movimento sindical que nós temos. E essa não foi a primeira não. Tive outras experiências com o movimento sindical. É tanto que, agora, eu não tenho interesse nenhum em atender qualquer solicitação do movimento sindical. Às vezes eu vou, só para ver se tem algum sinal de vida, [...] mas não tem. [...] Inclusive uma agora, recente [...] Era a coisa mais horrorosa que tem. Queria utilizar tudo só do ponto de vista do controle, realmente na questão do controlar, monopolizar e estabelecer pensamento único. E, aí, o preço que eu cobrei, não se dispuseram a pagar. (Silva, in: Paciornik, 2013, p. 205)

Ainda assim, Silva produziu mapas de risco para alguns sindicatos, como o Sindicato dos Trabalhadores da USP (Sintusp), para o qual, numa interface "saúde do trabalhador/local de trabalho", realizou os mapas de algumas unidades, como a Física e a Química.

Silva argumentava que as tecnologias de comunicação mais 
presentes no final da década de 1970, como o telefone, poderiam ampliar a transparência do movimento sindical até nos momentos que a historiografia hoje caracteriza como centrais para o restabelecimento da democracia, como as assembleias metalúrgicas em São Bernardo, no estádio da Vila Euclides. ${ }^{14}$ Trabalhando numa empresa com infra-estrutura informática de ponta no final dos anos 1990, esta percepção se tornou praticamente uma epifania para Silva:

Quando eu entrei nessa empresa, $[\ldots]$ eu caí numa panela de tecnologia. [...] Eu ficava besta, porque [...] [q]ualquer nível de problema que existisse agora, às $9 \mathrm{~h}$ da manhã, às $15 \mathrm{~h}$ de hoje estava resolvido. [...] Porque entravam imediatamente algumas pessoas fazendo pesquisa no mundo inteiro. Encontravam solução em Israel, na França, nos Estados Unidos. À tarde já estava negociado, entendido o problema e solucionado. Um negócio doido. Quando eu vi isso, quando eu vi essa possibilidade, eu digo: "Putz, tá toda a possibilidade agora de colocar a palavra de ordem do Marx: 'Trabalhadores do mundo: Uni-vos"'. [Foi a] primeira vez que eu vi que eu podia [...] me comunic[ar] com qualquer trabalhador em qualquer parte do mundo sem atravessar fisicamente o oceano. Todas as condições estão dadas, o capitalismo desenvolveu a possibilidade de produzir a aproximação de todos os trabalhadores do mundo. [...] [No entanto, a]inda estamos na ditadura dos dirigentes. Só a cúpula dos movimentos sindicais se encontra em congressos internacionais. Mas hoje já dá para

14 Diante do fato de que "muita gente não sabe ler e muitos que leem não entendem o que está escrito", Silva imaginou um sistema telefônico de informação do tipo "0800": "digite 1 para ouvir a opinião do Lula. Digite 2 para ouvir a opinião do Alemãozinho. Digite 3 para ouvir a opinião do Osmar. [...]. Então, [...] eu ligava para o 0800 e ouviria as três posições. Ia para a assembleia já com o caso pensado, discutido em família, amigos. Sabia por ouvir a voz de cada um no 0800." (Silva, in: Paciornik, 2013, p. 206).

Filosofia e Educação - ISSN 1984-9605

Volume 6, Número 3 - Outubro de 2014 
eu falar diretamente com a pessoa de uma fábrica. [...] Faço contato direto. (Silva, in: Paciornik, 2013, p. 209)

Para Silva, "todas as condições estão dadas, o capitalismo desenvolveu a possibilidade de produzir a aproximação de todos os trabalhadores do mundo". Mas, assim como Walter Benjamin (1994) num outro momento histórico, ele não constata o poder revolucionário das TICs sem imediatamente fazer a constatação complementar de que esse poder não está sendo aproveitado pelos explorados. "Ainda estamos na ditadura dos dirigentes". Era, portanto, central para Silva o uso das TICs para a "socialização da informação", de foma "que a informação chegasse em toda a base ao mesmo tempo que chega para o dirigente".

A diretoria do sindicato discutia a questão, vinha discutindo a questão meses e meses a fio, negociação com os patrões, possibilidades e tal. Só que essas discussões não saíam do âmbito de meia dúzia do entorno da diretoria. Não era uma discussão que chegasse na fábrica. [...] Aí, quando chega na assembleia, você, enquanto dirigente, apresenta todas as possibilidades que você pensou. Coloca as questões e oferece duas alternativas para votar. Dá cinco minutos para aquela massa de 60 mil pessoas pensar. Democracia, não é? (Silva, in: Paciornik, 2013, p. 205)

Como Marx (1847), quando associou o moinho ao modo de produção feudal e a máquina a vapor ao modo de produção capitalista que, em meados do século XIX, florescia na forma de indústria; ou como Simondon (1969), quando associou os elementos técnicos às artesania, os indivíduos técnicos ao industrialismo e os conjuntos técnicos à sociedade da 
informação que, naquele pós-Segunda Guerra Mundial, começava a se concretizar; ou Deleuze (1992), quando associou as máquinas simples às sociedades antigas de soberania, as máquinas energéticas às sociedades disciplinares e as máquinas informacionais às sociedades de controle que, a partir dos anos 1970, passaram definitivamente da ficção científica para o cotidiano; Silva também propõe uma analogia sociotécnica quando distingue a "democracia do microfone" (que ele compara a uma ditadura, pois o tempo limitado de fala limita a participação na discussão) de um outro tipo de democracia baseado no acesso aberto a bancos de dados com informações atualizadas (quando todos os envolvidos teriam recursos para se organizar localmente e assim participar mais ativamente das decisões coletivas).

Se você desse uma fração de segundo para 60 mil pessoas falarem, ninguém ia dizer nada, não ia conseguir ser entendido. Falar em uma fração de minuto, não ia colocar sequer um pensamento inteiro. Você democratizaria e significaria o desastre, ninguém ia entender nada, a assembleia seria [...] inútil. Então, [...] ali, só poucos podem falar. Porque, se 20 pessoas forem para falar 3 minutos, isso aí é 1 h. Se tiver uma réplica, qualquer coisa, já são $2 \mathrm{~h}$ de assembleia. Agora imagina no sol, todo mundo em pé. 60 mil pessoas, $2 \mathrm{~h}$ de assembleia? Sem chance. [...] Se, antes do dia de uma assembleia geral, você fizesse assembleias regionais, reunindo menor número de pessoas, mas que discutisse todas as questões. E que cada assembleia geral tirasse dois oradores ou três, no máximo, para falar para a assembleia geral, você teria todas as informações mais discutidas. (Silva, in: Paciornik, 2013, p. 205-6) 
Trata-se, portanto, de um problema de ampliação, por meio de um uso politicamente engajado de TICs, do acesso à informação relevante, no momento relevante, para que as pessoas tenham elementos a partir dos quais amadurecerem posicionamentos rumo a decisões mais genuinamente coletivas. E vemos que não se trata apenas de um discurso superficial, mas a enunciação de sua própria trajetória de vida.

Em 1993, Silva participou de uma última greve como metalúrgico, foi demitido e desistiu de procurar trabalho na área, coisa cada vez mais difícil de conseguir, dada sua história. Passou a viver, ou como dizia, "sobreviver", basicamente do geoprocessamento de dados: "era mais para pagar as dívidas. E estava sempre assim, correndo da mão para a boca, da mão para a boca" (Silva, in: Paciornik 2013:205). Nesse mesmo período, uma dúvida política assumiu o centro de seus questionamentos: “[E]u estava com muitos dados sem um método de apropriação. Porque a grande questão é como se apropriar, como o cidadão comum se apropria das bases de dados hoje". (Silva, in: Paciornik, 2013, p. 205-6)

E foi aí, ao entrar em contato com a obra de Milton Santos, que lhe adveio mais uma epifania voltada para a dimensão local.

Quando eu li esse artigo ["Elementos espaciais, uma questão de método"], [...] encaixou tudo o que eu estava fazendo [...] com o método desenvolvido pelo Milton Santos. Ele trazia a questão dos elementos espaciais básicos e a relação do indivíduo com o território. Começou o conceito da "área de vivência", que é [...] [onde o indivíduo] absorve a informação, em termos territoriais. É na área onde ele corta o cabelo, ele compra, bebe, joga, se diverte. [...] É nessa área de predominância de circulação que ele pega as informações. É na quitanda, $[. .$.$] no barbeiro, no cabeleireiro. Vai juntando e$ 
constrói, nesse ambiente, o saber popular, que é a base da movimentação dele. Quando eu descobri isso, descobri a possibilidade de juntar o saber popular e agregar o saber científico, na mesma escala. E aí se dá a revolução, se dá um salto de qualidade, porque o saber popular começa a ter base científica. E o saber científico começa a ter a possibilidade de reforçar, de utilizar a força do saber popular. Então isso dá um caldo de alteração da situação. (Silva, in: Paciornik, 2013, p. 205-6)

Em 1999, Silva foi convidado para dar um curso de informática na zona sul de São Paulo, por meio de uma parceria entre o Instituto Lidas e o que era então mais uma ONG assistencialista na periferia, chamada Casa dos Meninos.

\section{Casa dos Meninos, um encontro feliz}

O Jardim São Luis ${ }^{15}$ é um distrito na zona sul da cidade de São Paulo situado a cerca de 18 quilômetros da Praça da Sé. Limita-se ao norte com o distrito do Campo Limpo e ao sudoeste, com o distrito do Capão Redondo. De acordo com a divisão territorial da prefeitura de São Paulo, faz parte da Subprefeitura do M'Boi Mirim. Sua área é de 24,70 km² e, no último censo do IBGE, em 2010, figurava com 267.871 habitantes, apresentando uma densidade demográfica de 10.845 habitantes por $\mathrm{km}^{2}$, mais alta que a média paulistana, de $7.430 \mathrm{hab} / \mathrm{km}^{2}$; Abrigava 2,4\% dos 11.253 .503 moradores da cidade. $^{16}$

$15 \mathrm{O}$ nome Jardim São Luis é grafado de forma diferente por instâncias e áreas diferentes do poder público, a Saúde tende a usar a grafia com z, Luiz; outras áreas escrevem com acento no i, Luís. Optei por Luis sem z e sem acento pois esta é a grafia utilizada pela Casa dos Meninos.

16 IBGE. Censo de 2010.

Filosofia e Educação - ISSN 1984-9605

Volume 6, Número 3 - Outubro de 2014 
A Casa dos Meninos é uma associação, fundada em 1962, no Jardim São Luís por um grupo de empresários preocupados com uma questão que então emergia envolta em gravidade: o alto número de crianças em situação de abandono. A Casa surgiu como um orfanato masculino que abrigava 50 meninos abandonados por suas famílias, derivando daí o nome que a identifica até hoje. Permaneceu subsidiada por esse grupo de empresários até 1978, quando eles se afastaram da associação e esta foi assumida por moradores do bairro, mantendo um caráter de forte preocupação com a assistência social no local e assumindo uma estrutura típica de ONG.

A Casa dos Meninos se situa na Rua Yoshimara Minamoto, número 656, dentro do distrito do Jardim São Luís, e no bairro do Jardim Fim de Semana. ${ }^{17}$ A construção principal situa-se no topo de um terreno em declive, gramado e arborizado, com a casa perpendicular à rua, suas doze janelas da frente ao fundo, e cinco grupos de dois bancos de madeira a se estender ao longo da lateral da casa. O terreno é triangular, e entre a vegetação destacam-se um grande pinheiro, que balança sob o forte vento de uma área pouco verticalizada, uma árvore com flores de um vermelho forte, e um pequeno arbusto com flores brancas. Para além da construção principal, há uma segunda construção, menor, mas também de dois andares, em cujo primeiro andar funciona uma sala para reuniões e estudos dos representantes da Escola Procópio Ferreira, ${ }^{18}$ e que tem em seu segundo andar um conjunto

17 Para a pesquisa que resultou em Paciornik (2013), foi elaborado um pequeno vídeo apresentando o espaço físico da Casa dos Meninos e um pouco do que lá existe. Esse vídeo pode ser visto em: < http://vimeo.com/45852671>. Acessado em: 13 de setembro de 2014.

18 A Escola Municipal de Ensino Procópio Ferreira é localizada no Jardim Fim de Semana, dentro do distrito do Jardim São Luis, na zona sul da cidade de São Paulo. Esta escola se diferencia de muitas outras escolas municipais por contar com 1513 alunos, sendo uma das mais populosas entre as escolas municipais (a média é de pouco mais de 700 alunos). De 2005 para 2009, o Índice de Desenvolvimento da Educação Básica (Ideb), médio da rede municipal de São Paulo para a oitava série subiu de 4,1 para 4,2 (numa escala que vai de 0 a 10), e o da EMEF Procópio Ferreira desceu de 4 para 3,6. Em finais do ano de 2010, a Casa dos Meninos e a direção da EMEF Procópio Ferreira começaram uma parceria visando mudar esta situação. Mais informações em Paciornik (2013, p. 51-

Filosofia e Educação - ISSN 1984-9605

Volume 6, Número 3 - Outubro de 2014 
de documentos do movimento de defesa dos direitos da criança e do adolescente de toda a cidade de São Paulo, acervo este que deve ser transferido para o arquivo do Centro de Documentação e Memória (Cedem), da Universidade Estadual Paulista (Unesp), na Praça da Sé, no centro da cidade de São Paulo.

A Casa dos Meninos é composta por um conjunto muito interessante de práticas, discursos e pessoas. Creio que a pergunta central a partir da qual é possível sintetizar os esforços e práticas da Casa, é a que foi feita por Luana Bhering, integrante da Casa dos Meninos e do Conselho Municipal dos Direitos da Criança e do Adolescente: "Qual é a condição da felicidade?" Mais que a pergunta, a resposta que ela mesma deu é uma síntese:

\begin{abstract}
Nossa perspectiva é coletiva. Se a gente está feliz, está contente, está realizada. Ninguém aqui morreu de fome, a gente está com casa, com roupa, com comida. A gente como núcleo tenta realizar na prática para todos isso. É difícil, porque o individualismo está sempre aí tentando...
\end{abstract}

Do ponto de vista teórico, pode-se dizer que a prática deles não se reveste só de finalidade, mas também de uma forma de, apesar das adversidades (e as há), experimentar de forma coletiva uma felicidade no cotidiano. Pode-se também dizer que o projeto político deles visa uma felicidade coletiva, com satisfação psíquica e material para todos. Ou ainda, que o combate ao individualismo, marca do capitalismo contemporâneo, é fundamental na socialização das riquezas. Mas talvez melhor mesmo fosse dizer que, para o projeto da Casa dos Meninos, se trata de sobretudo não

67).

Filosofia e Educação - ISSN 1984-9605

Volume 6, Número 3 - Outubro de 2014 
"adiar para o outro século a felicidade coletiva". ${ }^{19}$

Como vimos, em 1999 a direção da Casa convidou o Instituto Lidas para o que seria um pontual curso de informática para qualificação profissional dos jovens da região. Silva aceitou realizar o projeto, mas sob algumas condições. Em primeiro lugar, como o espaço não contasse com internet, Silva estabeleceu que, sem a instalação da rede, não aceitaria fazer o projeto. Além disso, os computadores disponíveis eram velhos PCs 486 diante desse cenário, Silva estipulou que, sem a configuração mínima de um PC com processador Pentium e com modem para acessar a internet, ele também não levaria o curso adiante. Por fim, Silva expôs que o conteúdo do curso não deveria ser apenas informática, mas a informática em suas relações com o território. A direção da Casa aceitou os termos e assim se iniciou a parceria com o Instituto Lidas, que mudaria em definitivo a história da Casa dos Meninos e um tanto da história do bairro.

Em 2001, Silva foi convidado para a diretoria da Casa e os processos de mudança se aceleraram. Em 2003, uma parte da juventude local que já havia participado de projetos na Casa começou a se aproximar da direção e se confrontar com a então principal diretora, Diana. Em 2006, deu-se uma saída coletiva de cinco educadores que eram, segundo a ex-presidente e ainda integrante da Casa Fátima Rodrigues, "mais ligados ao modelo tradicional de ONG". Um grupo de jovens entre 15 e 20 anos assumiu a Casa - ainda segundo Rodrigues, "cometendo responsabilidades e irresponsabilidades". Em 2008, o conjunto da direção decidiu cessar os convênios com a Secretaria de Assistência Social e buscar a autonomia financeira por outros meios, deixando de depender centralmente de uma

19 Trecho do Poema "Elegia 1938" de Carlos Drummond de Andrade. A estrofe inteira é: "Coração orgulhoso, tens pressa de confessar tua derrota / e adiar para outro século a felicidade coletiva / aceitas a chuva, a guerra, o desemprego e a injusta distribuição / porque não podes, sozinho, dinamitar a Ilha de Manhattan”.

Filosofia e Educação - ISSN 1984-9605

Volume 6, Número 3 - Outubro de 2014 
única fonte governamental.

Dentre os processos desenvolvidos na Casa, os atuais integrantes destacam a centralidade da ideia da Cooperativa de Logística Urbana (Cooplurb). A Cooplurb, que não está mais ativa, possuía três grandes objetivos: reunir informações que pudessem ser distribuídas para a sociedade civil, criando o que passaram a chamar de Base Comum de Conhecimento Cidadão (BCCC); dialogar e, quando necessário, confrontar e contestar os poderes públicos a partir do conjunto de informações organizadas nesse formato; e a meta de que o projeto fosse capaz de se auto sustentar.

No que se refere à Base Comum de Conhecimento Cidadão (BCCC), trata-se de uma plataforma que reuniria diversos tipos de conhecimento de diversas áreas e fontes e as situaria sobre mapas. Essa base seria abastecida por jovens que, duas vezes por semana, colheriam informações no entorno de suas casas e as disponibilizariam num sistema via internet. Seria esta base a que permitiria uma aproximação do conjunto de informações e conhecimentos científicos já existentes em diversos sistemas de informação, com o saber popular existente em cada morador. Seria também a partir desta Base que o território se "desocultaria" para cada jovem e cada morador, e adquiriria uma inteligibilidade política maior. É na BCCC que estaria, na prática, a articulação entre: (1) o conceito de "área de vivência", proposto por Milton Santos; (2) os sistemas de informações públicas (IBGE, prefeitura, Estado etc.); e (3) dados locais e de geoprocessamento gerados pela Casa dos Meninos.

Em texto conjunto com Diamantino Pereira e Gustavo Souza, Silva definia a BCCC como:

Base que deve cumprir o papel de permitir que todos os

Filosofia e Educação - ISSN 1984-9605

Volume 6, Número 3 - Outubro de 2014 
cidadãos possam ter acesso ao conjunto das informações necessárias para fundamentar seus desejos de mudança. [...] A estrutura desse sistema de informações deve ter como ponto de partida: uma divisão territorial de base censitária reconhecida pelos cidadãos no cotidiano de suas relações; um conjunto de informações existentes e disponíveis estruturadas com metodologia reconhecida pelos poderes públicos e pela comunidade; um padrão e um campo relacional que seja necessariamente o território de vivência do cidadão; uma tecnologia amigável desenvolvida em softwares livres capaz de suportar as bases de dados; uma pedagogia de utilização dessas informações; e, agentes de difusão. (Pereira; Silva; Souza, 2007)

A ideia, posta em prática em diversos projetos posteriores, é que jovens do local circulassem dentro da sua área de vivência e recolhessem informação acurada sobre o território, alimentando um banco de dados georreferenciado e completo, que serviria tanto para organização política e contestação, quanto como uma base que pudesse ter parte dos dados vendida pelos próprios cooperados, fomentando o comércio local e trazendo renda a esses jovens. $\mathrm{O}$ ato de passagem pelo território para preenchimento do banco de dados, os integrantes da Casa chamam de "percorrida".

Um exemplo de uso político da "percorrida" foi o Movimento Creche para Todos, de 2008. A partir de "percorridas" com um formulário especificamente criado para esse fim, e do georreferenciamento dessas informações, foi possível mostrar às mães e parentes de crianças sem creche o quanto essas crianças estavam concentradas num território muito pequeno dentro do distrito. É aí que está a diferença central entre os grandes dados e os números da cidade e dos distritos, de um lado, e a informação 
georreferenciada de forma inteligível e próxima às pessoas, de outro. $\mathrm{O}$ número oficial de mais de cem mil crianças sem creche na cidade, ou mesmo o número de milhares de crianças sem creche no distrito do M'Boi Mirim, não dariam tal visibilidade e concretude à pauta. Os dados da "percorrida" auxiliaram na criação de um movimento local e, de fato, foram abertas creches junto às Escolas Procópio Ferreira e Airton Arantes.

Outro uso possível da BCCC que os integrantes da Casa vislumbram é a socialização de riquezas dentro do território, entendendo "riquezas" para além do meramente financeiro: avaliam que em toda casa de morador há riquezas, sejam estas livros, saberes específicos, equipamentos eletrônicos, sobras de material de construção ou mesmo um espaço livre na garagem que pode sediar um grupo de estudos ou o acesso a acervos digitais construídos. Chegou-se a desenvolver um sistema digital para organizar a troca de livros (físicos, os volumes impressos) de casa a casa, mas tiveram problemas com a padronização dos registros, pois o sistema ISBN da Biblioteca Nacional não estava aberto e disponível. ${ }^{20}$

Outro exemplo de algo que só um sistema muito próximo ao território e ao saber local (com dados que não poderiam ser obtidos diretamente junto ao poder público), como o BCCC, poderia realizar, é o da redistribuição das sobras de material de construção. Argumentam que é uma prática muito comum na periferia realizar pequenas reformas ou subir um andar nas casas através dos famosos "puxadinhos", e que quase sempre sobram materiais como areia, cimento e cascalho, que ficam anos acumulados nos quintais, e que, dado o declive da região, acabam escorrendo parcialmente para a rua quando chove. É possível, como disse Fátima Rodrigues, "literalmente andar na rua sobre riqueza do território

20 Fizeram uma reunião com a Biblioteca Nacional no Rio de Janeiro, mas esta não resolveu parte dos problemas do sistema e do acesso público a este.

Filosofia e Educação - ISSN 1984-9605

Volume 6, Número 3 - Outubro de 2014 
sendo desperdiçada", um desperdício que poderia ser evitado de um sistema permitisse a sua redistribuição racional pelo território. Outra possibilidade mencionada seriam aulas de conhecimentos específicos (marcenaria, informática, inglês ou qualquer outro saber) e um sistema georreferenciado na internet para organizar essas trocas locais. Os integrantes da casa planejam, antes mesmo da criação de uma BCCC com uma arquitetura robusta de software, criar sistemas que deem conta de socializar essas riquezas. Afirmam que, no fundo, organizar essas trocas não visa apenas manter o dinheiro na região ou diminuir desperdícios, mas se insere em uma mudança cultural mais profunda, da substituição de uma cultura capitalista e de acumulação por uma cultura mais solidária.

Além da idealização da $\mathrm{BCCC}$, foi no projeto Cooplurb que se descobriu um ajuste das informações sobre tamanho do território e dados públicos existentes que pôde tornar palpável e visível o conceito de "área de vivência". A partir do método e das áreas presentes na pesquisa "Origem e Destino", realizada pela Companhia do Metrô de São Paulo, os envolvidos no projeto derivaram um tamanho otimizado entre território local e presença de dados públicos georreferenciáveis nessa escala. Essa junção foi chamada de Unidade de Planejamento Participativo (UPP). A localização exata da área onde se concentram os trabalhos da Casa dos Meninos é a UPP de número 254, entre as 270 nas quais a cidade de São Paulo se divide. O uso da UPP é justificado pelos integrantes da Casa a partir de uma crítica do uso do conceito de "bairro", muito ruim para se trabalhar em georreferenciamento por não ter os limites claramente definidos (é comum que um mesmo endereço apareça com nomes diferentes no campo "bairro". Para integrantes da Casa, a menor divisão territorial adequada para se trabalhar com georreferenciamento é o setor censitário desenhado pelo IBGE, pois é bastante completo (segundo eles, é um dos sistemas mais 
completos de informação sobre o território no mundo), contando com cerca de 2.500 informações, sobre uma área de aproximadamente 300 domicílios. Os distritos entre os quais a prefeitura divide a cidade (e os respectivos dados públicos) respeitam os setores censitários, e diversos dados de outros agentes públicos e privados também. Entre o setor censitário, muito pequeno para configurar uma "área de vivência", e o distrito, tão grande que causaria perda de identificação entre as pessoas e o território, foi considerado que a UPP apresentava tamanho intermediário otimizado e útil para dar inteligibilidade ao conceito de "área de vivência".

Em 2004 a Câmara dos Vereadores de São Paulo concedeu o Prêmio Milton Santos à Casa dos Meninos pelo projeto da Cooplurb. A Casa ganhou o prêmio, mas, na prática, não levou. Isso porque parte do prêmio, além de um troféu de metal, era a recomendação à prefeitura, por parte da Câmara, para que adotasse o projeto, já que era referência para a cidade. No entanto, a prefeitura não adotou a sugestão da Câmara dos Vereadores e não transformou a Cooplurb em política pública.

A partir da Cooplurb, ${ }^{21}$ diversos outros trabalhos da Casa dos Meninos passaram a utilizar a área da UPP-254 para cruzar mais informações e dar maior inteligibilidade a essa informação para os jovens e moradores. A Cooplurb teve muita dificuldade de se legalizar e se manter com estatuto de cooperativa, e hoje está desativada como entidade jurídica, mas é basicamente a partir dos métodos então desenvolvidos, e dos jovens que se formaram nesse processo, que a Casa se sustenta hoje, e a construção efetiva de uma BCCC virou um marco e um objetivo político que orienta as discussões e lutas. "A nossa visão estratégica é uma Cooplurb que de fato cubra o território da cidade toda", diz Fátima Rodrigues. Isso porque a avaliação na Casa é a de que esse processo concretizou, na prática, o que

21 Mais informações sobre a Cooplurb em Pereira, Silva e Souza (2007).

Filosofia e Educação - ISSN 1984-9605

Volume 6, Número 3-Outubro de 2014 
consideram ser o tripé de sua atuação: juventude, território e tecnologia. A Cooplurb seria o que poderia dar materialidade a esses três elementos, dentro da visão maior de criação de uma nova cultura política de esquerda, que transforme e dê potência para os processos de luta contra as desigualdades do sistema capitalista. ${ }^{22}$

\section{Vida e pensamento}

Em qualquer reunião que eles estiverem, qualquer coisa que se delibera, na hora, eles [os integrantes da Casa] colocam: onde, como, quando? $[\ldots]$

[A]contece uma coisa, acontece num lugar. Se eles não plotarem, se eles não geocodificarem essa informação, eles não fazem nada. [...] [É] como se não existisse. [...] A informação tem que estar no local e esse local tem uma voz. Nesse local, eles já vão imediatamente e verificam todos os dados do Censo, porque nós criamos um mecanismo para isso. Verificam todos os equipamentos sociais e serviços existentes. Verificam quantas empresas de comércio, serviço e indústria. E, aí, eles associam todas as questões com a questão política. Então é outra condição de se fazer política. A demagogia é muito mais difícil de entrar no cotidiano deles, porque quando eles não veem a possibilidade de mudar, de fazer, eles já ficam com o pé atrás no sentido de: "Precisa alguma coisa aqui. Tá faltando alguma coisa".

A questão da análise concreta está colocada. E isso é um

22 Mais informações sobre a Casa dos Meninos e outros projetos por ela desenvolvidos podem ser encontradas em Paciornik (2013:11-67).

Filosofia e Educação - ISSN 1984-9605

Volume 6, Número 3 - Outubro de 2014 
elemento novo na política. A gente está juntando coisas que eu tive muita dificuldade na minha juventude. [...] Agora, o bicho pegou. É essa a minha alegria e é a questão velha lá que eu levantei no primeiro congresso de UBES. Tenho o que comemorar. Está pegando, está pegando. (Silva, in: Paciornik, 2013, p. 213).

Encerrando assim a entrevista que concedeu a Agnes Mariano em 2009, Silva mostra que, mesmo depois de apanhar tanto nos desvãos da vida e da política, não deixa nunca de sorrir. Há na Casa dos Meninos o legado de Silva, que compreendeu muito cedo a importância, o poder e as possibilidades das TICs nas lutas de transformação do sistema de produção e de exploração. É o legado de uma prática que em 1988 já se utilizava das ferramentas de TICs disponíveis para impulsionar luta social, que então já realizava georreferenciamento usando o sistema operacional DOS e assinalando com canetas os pontos em mapas de papel. E de uma teoria que percebe a tecnologia como essencial na criação das condições objetivas de apropriação do território, na criação de condições de transparência política e financeira (centrais para projetos coletivos e para a existência de confiança política) e na diminuição da assimetria informacional (e consequentemente de capacidades discursivas e decisórias) entre representantes e representados, entre direção e base. Silva costumava dizer que a Casa dos Meninos é um "laboratório de construção do novo", o que significava um espaço de experimentação política para construção de uma nova prática e de uma nova cultura política; que soubesse se utilizar efetivamente das potências trazidas pelas tecnologias, compreender de fato o território e organizar a política através da vivência concreta do povo e da classe; e que também conseguisse se livrar de uma série de vícios políticos de cupulismo, 
falta de transparência e de discussão coletiva que Silva via na cultura política da esquerda brasileira, e que ele chamava de "ditadura dos dirigentes". Por tudo isso, a mobilização de TICs, por Silva e pelos integrantes da Casa dos Meninos, para a organização política popular local, nos parecem casos privilegiados daquilo que Simondon chamou de "mecanologia".

Em maio de 2010, Silva concedeu uma entrevista a Guilherme F. Paciornik (2013:24-5) na qual reiterou sua trajetória de luta baseada num uso emancipador das TICs, com declarações como: "as novas tecnologias podem modificar a cultura política da esquerda"; "o instrumental para fiscalização efetiva da direção pela base não existia, hoje existe"; "os mapas construídos em tempo real [com os jovens da periferia], são subjetivos, mas constroem encaminhamentos objetivos"; "vai haver uma tentativa [das velhas elites] de colocar o usuário de tecnologias da informação como se fosse um usuário de drogas. Mas de drogas digitais, o que vai ser um problema muito grave, uma tentativa de, tal qual o rádio e a televisão antes, alienar o usuário"; "estamos num momento crítico na possibilidade de uso de TI de forma emancipadora, da constituição dos indivíduos como sujeitos. Inclusive o papel da esquerda. Temos de encontrar um caminho"; entre tantas outras.

Em sete de junho de 2011, após uma internação por problemas cardíacos, Silva morreu aos 61 anos de idade.

Ainda em 2011, um coletivo de hackers e de desenvolvimento de software livre, ligado a diversos Pontos de Cultura e ao Pontão de Cultura Nós Digitais, surgiu, com sede principal em São Carlos, e foi batizado como Lab Macambira, em homenagem ao pseudônimo literário e revolucionário de Silva. ${ }^{23}$ Há também um vídeo em homenagem a Silva produzido pelo

23 Pode ser visitado em $<\mathrm{http}: / /$ labmacambira.sourceforge.net/>. Acessado em: $13 \mathrm{de}$

Filosofia e Educação - ISSN 1984-9605

Volume 6, Número 3 - Outubro de 2014 
IIEP, ${ }^{24}$ que cuida também do "Projeto Memória da Oposição Sindical Metalúrgica". ${ }^{25}$ Célio Turino, que foi Secretário de Cidadania Cultural do Ministério da Cultura nas gestões de Gilberto Gil e Juca Ferreira (a secretaria responsável pelo Programa Cultura Viva, o programa dos Pontos de Cultura) deu, em novembro de 2012, uma entrevista à revista Fórum, ${ }^{26}$ na qual homenageou Silva e propôs que a plataforma para o Cadastro Nacional dos Pontos de Cultura fosse chamada Plataforma Macambira, como tributo ao codinome que Silva adotou em sua luta contra a ditadura. Também muitos dos coletivos novos de cultura digital e dos pontos de cultura o conheciam. Uirá Porã, da prefeitura de Fortaleza e figura constante nas discussões de cultura digital e pontos de cultura, o lembrou no programa de televisão na internet organizado pelo coletivo Fora do Eixo, a POSTV, durante o Festival Internacional de Software Livre (FISL) em Porto Alegre, em julho de 2012. Fred do movimento de midialivrismo o citou em sua fala na Oficina de Inclusão Digital e Participação Social em Porto Alegre, em novembro de 2012. Em 2013, a Subprefeitura do M'Boi Mirim pediu à Casa dos Meninos que escolhesse uma praça sem nome na região, e há na região dezenas de praças sem nome, para que esta fosse nomeada pelo poder púbico como "Praça Cleodon Silva". A escolha está em processo, e provavelmente a praça escolhida será uma próxima ao endereço da Casa.

Os integrantes da Casa relatam que, de forma geral, os anos de 2011 e 2012 foram bastante difíceis. Houve perda de capacidade de articulação política e uma queda no uso do software livre e na produção de ferramentas.

setembro de 2014.

$24 \mathrm{O}$ vídeo pode ser visto em <https://www.youtube.com/watch?v=D7Lz82m2m2I $>$. Acessado em: 13 de setembro de 2014.

25 Cf.: <http://www.iiep.org.br/index1.html>. Acessado em: 13 de setembro de 2014.

26 A entrevista pode ser lida em $<$ http://www.revistaforum.com.br/brasilvivo/2012/11/30/a-lei-cultura-viva-venceu-maisuma-etapa-na-sua-corrida-de-obstaculos-agora-e-a-vez-da-plataforma-macambira/>. Acessado em: 13 de setembro de 2014.

Filosofia e Educação - ISSN 1984-9605

Volume 6, Número 3 - Outubro de 2014 
Como Luana Bhering colocou: "Desde que o Silva morreu não conseguimos mais produzir e utilizar novas ferramentas. O Silva tinha um jeito...conseguia conversar e fazer parcerias com desenvolvedores de ferramentas." Para além disso, houve uma paulatina separação entre Lidas e Casa dos Meninos devido, principalmente, a visões divergentes sobre como organizar o trabalho com um todo.

Por outro lado, o ano de 2013 começou com diversos bons auspícios para o trabalho da Casa e para o trabalho do Instituto Lidas. No Lidas, o Projeto CulturaEduca ${ }^{27}$ se desenvolveu bastante e tem a possibilidade de ser referência em projetos de dados públicos abertos e georreferenciados, tanto no Brasil, como em toda América Latina. Já a Casa dos Meninos e os integrantes que lá permaneceram foram paulatinamente retomando a capacidade de desenvolver ferramentas. Ainda em 2012, a Casa ampliou o trabalho para outra escola da região, a Escola Municipal Professor Airton Arantes Ribeiro Junior, e passou a trabalhar cada vez mais próxima à Associação de Moradores Visão e Ação. No começo de 2013, a Casa assistiu, depois de mais de dois anos de atuação na Escola Procópio Ferreira, seu trabalho em educação ser reconhecido por outras escolas da região e da cidade e, em maio, fechou parceria para oficinas de georreferenciamento do território com a Diretoria Regional de Educação (DRE) de Itaquera e Aricanduva (zona leste da cidade de São Paulo), parceria que já conta com a adesão de 31 escolas dessa região. Em agosto de 2013, a Subprefeitura do M'Boi Mirim também demonstrou interesse em firmar uma parceria com a Casa e expandir o trabalho na região. Na mesma

27 O Projeto CulturaEduca é um grande site de georreferenciamento de diversos bancos de dados públicos, de vários ministérios, com ênfase em dados e equipamentos culturais no entorno das escolas, e com espaço para participação e discussão das próprias escolas dentro do site. O site e o mapa piloto de Recife já realizado podem ser vistos em $<$ http://culturaeduca.cc/>. Acessado em: 13 de setembro de 2014. Este projeto é realizado junto ao Ministério da Cultura e em parceria com o Ministério da Educação.

Filosofia e Educação - ISSN 1984-9605

Volume 6, Número 3 - Outubro de 2014 
data e da mesma forma a DRE Campo Limpo (que conta com 178 escolas em seu território) também demonstrou o mesmo interesse. Em 2014 a Prefeitura de São Paulo encampou a Conferência Permanente, e o Conselho Municipal dos Direitos da Criança e do Adolescente da Cidade de São Paulo (CMDCA/SP) lançou o sistema oficial para todas as inscrições das conferências regionais da cidade. ${ }^{28}$

São interessantes as formas como os pensamentos de uns se mantém vivos nos corpos de outros. Se foram as reflexões e o engajamento de Silva que despertaram o interesse acadêmico que originou e guiou a pesquisa que resultou neste texto, isso significa que, de alguma forma, suas ideias estão presentes nas reflexões aqui apresentadas. "Na realidade, existe um parentesco enorme entre vida e pensamento" (Simondon 1969:60). Neste sentido então, não há nada mais justo do que atender a um pedido dos próprios integrantes da Casa dos Meninos, e com o qual concordamos, e encerrar também este texto com a antiga, mas não velha, saudação comunista: Companheiro Cleodon Silva, Presente!

\section{Referências}

BENJAMIN, Walter. 1994. A obra de arte na era de sua reprodutibilidade técnica. (Trad. Sérgio P. Rouanet) In: Magia e técnica, arte e politica: ensaios sobre literatura e história da cultura. Obras Escolhidas Vol.1. São Paulo: Brasiliense,

28 A Conferência Permanente surgiu da crítica ao que era considerado um longo espaçamento entre as conferências oficiais de direitos da criança e do adolescente realizadas a cada dois anos - e como forma de resposta às organizações sociais da sociedade civil durante os períodos de intervalo. $O$ grupo, que já participava da organização da Conferência dos Direitos da Criança e do Adolescente (CDCA) de forma local desde 2003, passou a ter um trabalho reconhecido na cidade inteira em 2007, com a construção de um "Diagnóstico dos direitos da criança e do adolescente da cidade", bem como com a construção de um site, cuja versão atual é: $<$ http://www.conferenciapermanente.org.br/2014/\#>. No site, se uma pessoa se cadastra e coloca seu CEP, tem acesso às discussões e metas previstas na sua área de vivência, e pode votar naquelas que achar prioritárias, além de poder acompanhar o andamento político da resolução dos problemas elencados.

Filosofia e Educação - ISSN 1984-9605

Volume 6, Número 3-Outubro de 2014 
p.165-96.

DELEUZE, Gilles. 1992. Post-scriptum sobre as sociedades de controle. In: Conversaçoes 1972-1990. (trad. Peter P. Pelbart) Rio de Janeiro: Ed.34, p.219-26. [1990]

GARCIA DOS SANTOS, Laymert. 2003. A informação após a virada cibernética. In: Laymert Garcia dos Santos; Maria R. Kehl; Bernardo Kucinski; WalterPinheiro. Revolução tecnológica, internet e socialismo. São Paulo: Editora Fundação Perseu Abramo, p.9-33.

MARX, Karl. 1847. Miséria da Filosofia. Marxists.org <http://www.marxists.org/portugues/marx/1847/miseria/index.htm $>$.

Acessado em: 13 de setembro de 2014.

PACIORNIK, Guilherme F. 2013. Movimentos sociais e as novas tecnologias da informação e comunicação: um estudo de caso na zona sul da cidade de São Paulo, a Casa dos Meninos. Dissertação de Mestrado. Campinas: Programa de Pós-Graduação em Sociologia do IFCH/Unicamp. Disponível em: <http:/ /www.bibliotecadigital.unicamp.br/document/?code=000920115> PEREIRA, Diamantino Alves; SILVA, Cleodon; SOUZA, Gustavo de Oliveira C. de. 2007. O território e o lugar na vida cotidiana metropolitana. Scripta Nova. Revista Electrónica de Geografía y Ciencias Sociales vol. XI, n.245 (25). Disponível em: <http://www.ub.es/geocrit/sn/sn-24525.htm>. Acessado em: 13 de setembro de 2014.

SIMONDON, Gilbert. 1969. Du mode d'existence des objets techniques. Paris: Aubier-Montagne. [1958]. 